\title{
Insulinotherapy in diabetes melittus type I
}

\begin{abstract}
Diabetes Mellitus is a non-transmissible chronic disease, characterized by increased circulating glucose levels and caused by the destruction of pancreatic beta cells or the interruption of insulin production. It is a complex pathology that impairs the productivity, quality of life and the survival rates of patients. Considering that the periodic and appropriate treatment decreases and/or delays the probability of developing complications, the purpose of this study is to identify the most prescribed therapy for patients with DM1 assisted by the Specialized Component of Pharmaceutical Services on the state of Piauí, Brazil. It is an analytical cross-sectional study that uses a quantitative approach. The research focuses on the DM1 patients assisted by the SCPS, the organization responsible for dispensing high cost insulin. The research was performed in 2017, when 208 medical records were analyzed. This study was approved by Human Research Ethics Committee of the Faculdade Integral Diferencial (FACID) of DeVry Brasil group under protocol n ${ }^{\circ}$ 68644717.2.0000.5211. The most prescribed insulinization regimens are Glargine associated with Aspart $38 \%(n=79)$, followed by Glargine with Glulisine 32\% $(n=67)$ and by Glargine with Insulin Lispro $(n=44)$. The correct treatment of DM1 involves the use of two types of different insulins to simulate the basal secretion and the insulin peak post-meal. It is evidenced that the concomitant use of two types of insulins is a more effective treatment to insulin-dependent diabetics. The association of Glargine and Aspartate was the most prescribed in this study, and it was observed that patients that use only one type presented undesirable effects.
\end{abstract}

Keywords: insulin, diabetes mellitus, pharmaceutical care
Volume 7 Issue 2 - 2019

\author{
Gisele Lopes Cavalcante,' Maria dos \\ Remédios Mendes de Brito, ${ }^{2}$ José Virgulino \\ de Oliveira Lima, ${ }^{3}$ Maria Camila Leal de \\ Moura, ${ }^{3}$ Yara Maria da Silva Pires,' Paulo \\ Pedro do Nascimento, ${ }^{2}$ Jordanna di Paula \\ dos Santos Sousa ${ }^{3}$ \\ 'Department de Pharmacology, Universidade Federal do Piauí, \\ Brazil \\ ${ }^{2}$ Department de Pharmacology, Faculdade Integral Diferencial \\ Wyden, Brazil \\ ${ }^{3}$ Department de Pharmacology, Centro Universitário Santo \\ Agostinho, Brazil
}

\begin{abstract}
Correspondence: Yara Pires, Department of Pharmacology, Universidade Federal do Piaui, Campus Petrônio Portela-Ininga, Brazil,Tel +55 86 32 I5-5872, Email yah.pires@hotmail.com
\end{abstract}

Received: February 17, 2019 | Published: March 22, 2019

\section{Introduction}

Diabetes Mellitus is a non-transmissible chronic disease that affects thousands of people in the world. It is characterized by increased circulating glucose levels, once the body does not produce enough insulin or it is not able to properly use the insulin produced. This disease is subdivided into two main forms: In Diabetes Mellitus type 1 (DM1) the insulin is not produced, it is usually detected in childhood and adolescence; Diabetes Mellitus type 2 (DM2) occurs when the body produces insulin, however it is insufficient or there is cell resistance to absorb it. DM2 usually affects obese people after 40 years of age. DM1 is an autoimmune pathology, which may encompass the destruction of pancreatic beta cells or the interruption of insulin production, leading to metabolic imbalance. ${ }^{1}$ The treatment consists in daily insulin administrations, and there is a variety of therapeutic regimens of administration and different types of insulin. To be effective, it is also necessary to follow the posology, to monitor the blood glucose and follow-up diet and physical exercise. ${ }^{2}$ DM1 is a complex pathology difficult to be controlled, it is painful and it impairs the productivity, quality of life and the survival rates of patients. ${ }^{3}$ If DM1 is not properly treated, acute and chronic complications may occur. Thus, the periodic and appropriate treatment decreases and/ or delays the probability of developing these complications. ${ }^{4}$ Thus, the purpose of this study is to identify the most prescribed therapy for patients with DM1 assisted by the Specialized Component of Pharmaceutical Services on the state of Piauí, Brazil, and indicate the most effective.

\section{Methods}

It is an analytical cross-sectional study that uses a quantitative approach. The research focuses on the DM1 patients assisted by the Specialized Component of Pharmaceutical Services (SCPS) on Piauí state, as this organization is responsible for dispensing high cost insulins. The research was performed in 2017, when 208 medical records were analyzed. This research was developed respecting all the conditions of Resolution 466/12 of the National Health Council. It was submitted and approved by Human Research Ethics Committee of the Faculdade Integral Diferencial (FACID) of DeVry Brasil group, protocol $\mathrm{n}^{\circ} 68644717.2 .0000 .5211$. The date was organized into tables and graphs on Microsoft excel 2010.

\section{Results and Discussion}

The most prescribed insulinization regimens are shown in Graph 1. It can be observed that Glargine associated with Aspart was the therapy most prescribed ( $38 \% ; n=79)$, followed by Glargine with Glulisine $32 \%(\mathrm{n}=67)$ and by Glargine with Insulin Lispro $21 \%$ $(n=44)$. Others treatments were not statistically significant.

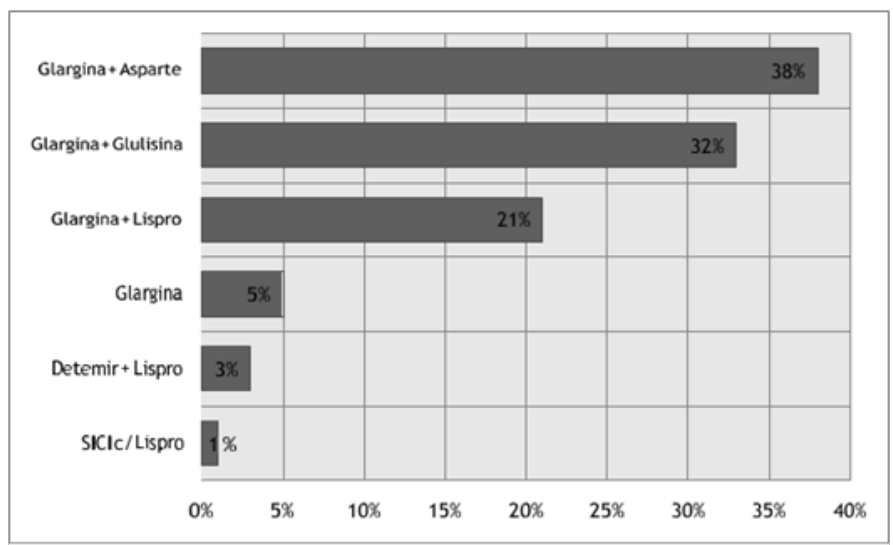

Graph I Most prescribed insulin regimens for DMI patients assisted by SCPS. 
Most DM1 patients assisted by SCPS undergone prior treatment, it means that before using the insulin analogs described on Graph 1, these patients used Regular and NPH insulins, however, this therapy was not effective and/or it was causing undesirable effects, leading to necessity of changing the medication. ${ }^{5}$ The correct treatment of DM1 involves the use of two types of different insulins to simulate the basal secretion and the insulin peak post-meal. This treatment can be performed with the application of multiple doses of insulin, with a syringe, pen or system of ongoing insulin infusion. ${ }^{5,6}$ However, it is observed that $5 \%$ of the diabetics are using only Glargine, which can impair the therapeutic result.

Glargine and Detemir are classified as long-acting insulin analogues, which simulate the peak of basal insulin secretion; while Lispro, Aspart and Glulisine are classified as faster acting insulin analogues, which simulate the peak of post-meal insulin secretion. ${ }^{7}$ Some advantages can be obtained after the replacement of Regular and NPH insulins by these analogues, especially regarding hypoglycemic events several and nocturnal. ${ }^{8}$ Several studies have demonstrated a lower frequency of hypoglycemia events in patients that use longacting insulin analogs, such as Glargine and Detemir, compared to NPH insulin users. It occurs due the absence or decrease of these insulins' peak. ${ }^{9,10}$ Studies have shown that the use of two daily doses of Detemir with Aspart is equally effective to control the glycemy to Glargine with Aspartin used once a day, however the association with Detemir presents less diurnal or nocturnal hypoglycemia crises. ${ }^{11,12} \mathrm{~A}$ meta-analysis that evaluated eight randomized trials, with 2576 adult DM1 patients, demonstrated a significantly lower frequency of severe hypoglycemia with Lispro compared to individuals who used Regular insulin. ${ }^{13}$ According to a recent evidence-based review, insulin Aspart provides a better glycemic control and less risk of hypoglycemia than Regular insulin. ${ }^{14}$

\section{Conclusion}

This research evidenced the importance of analyzing the pharmacotherapeutic profile of patients with type 1 diabetes mellitus to discuss treatments and to improve the care. This research confirms that the concomitant use of two types of insulins is more effective and provides better therapeutical results to insulin-dependent diabetics. The association of Glargine and Aspartate was the most prescribed in this study, and it was observed that patients that use only one type presented undesirable effects.

\section{Funding details}

None

\section{Acknowledgments}

None

\section{Conflicts of interest}

Authors have none to declare.

\section{References}

1. Miculis CP, Mascarenhas LP, Boguszewski M, et al. Physical activity in children with type 1 diabetes. Jornal de pediatria. 2010;86(4):271-278.

2. Chien SC, Larson E, Nakamura N, et al. Self-care problems of adolescents with type 1 diabetes in southern Taiwan. Journal Of Pediatric Nursing. 2007;22(5):404-409.

3. Oliveira JE, Junior RM, Vencio S. Diretrizes da Sociedade Brasileira de Diabetes 2017-2018. São Paulo: Editora Clannad; 2017. 91 p.

4. Guidoni CM, Olivera CM, Freitas OD, et al. Assistance to diabetes in the Unified Health System : analysis of the current model. Brazilian Journal of Pharmaceutical Sciences. 2009;45(1):37-48.

5. Davies MJ, Bergenstal R, Bode B, et al. Efficacy of liraglutide for weight loss among patients with type 2 diabetes: the SCALE diabetes randomized clinical trial. JAMA. 2015;314(7):687-699.

6. Milech A, Angelucci AP, Golbert A, et al. Diretrizes da sociedade brasileira de diabetes (2015-2016). São Paulo: AC Farmacêutica; 2016.

7. Ribeiro ME, Junior RD, Custodio R, et al. Continuous insulin therapy versus multiple insulin injections in the management of type 1 diabetes: a longitutinal study. Revista Paulista de Pediatria. 2016;34(1):86-90.

8. Eyzaguirre F, Codner E. Análogos de insulina: en búsqueda del reemplazo fisiológico. Revista médica de Chile. 2006;134(2):239-250.

9. Heise T, Nosek L, Rønn BB, et al. Lower within-subject variability of insulin detemir in comparison to $\mathrm{NPH}$ insulin and insulin glargine in people with type 1 diabetes. Diabetes. 2004;53(6):1614-1620.

10. Hermansen K, Davies M. Does insulin detemir have a role in reducing risk of insulin-associated weight gain?. Diabetes, Obesity and Metabolism. 2007;9(3):209-217.

11. Pieber TR, Treichel HC, Hompesch B, et al. Comparison of insulin detemir and insulin glargine in subjects with type 1 diabetes using intensive insulin therapy. Diabetic Medicine. 2007;24(6):635-642.

12. Becker T, Vermeulen MJ, Wyatt PR, et al. Prepregnancy diabetes and risk of placental vascular disease. Diabetes Care. 2007;30(10):2496-2498.

13. Mannucci E, Monami M, Lamanna C, et al. Prevention of cardiovascular disease through glycemic control in type 2 diabetes: a meta-analysis of randomized clinical trials. Nutrition, Metabolism and Cardiovascular Diseases. 2009;19(9):604-612.

14. Plank J, Bodenlenz M, Sinner F, et al. A double-blind, randomized, doseresponse study investigating the pharmacodynamic and pharmacokinetic properties of the long-acting insulin analog detemir. Diabetes care. 2005;28(5):1107-1112. 